\title{
Open e-University Phase II: Quality, Reliability and Security of Technical Systems: A Blended Learning Approach for a M.Eng.-Course
}

\author{
Bernhard Hoppe and Raphael Kurz
}

\begin{abstract}
In this paper we present the current status of the development of an M.Eng.-program in Q\&R (Quality and Reliability). The course is to be completed in part time and with distant learning in a blended learning approach. This project is driven by the strong demand from industry and society for well-trained Q\&R-Engineers and is funded by the German Government and part of Phase II of the Open-e-University project. Course content, instruction design, and teaching methods will be outlined.
\end{abstract}

Index Terms-Distant learning course design, blended learning, quality and reliability, sustainable infrastructure for further education, non-traditional students.

\section{INTRODUCTION}

"Aufstieg durch Bildung: offene Hochschulen: Upward mobility through academic training: Open universities" is an ongoing funding program of the German Federal Government (Ministry of Education and Research, BMBF) to initiate study programs for the academisation of non-traditional students and continuous education for practitioners. Open e-University is one out of 26 projects within this BMBF initiative [1], which started in 2011. It is a joint project of the Universities of Applied Science in Darmstadt and in Aschaffenburg (HS-Darmstadt and HS-Aschaffenburg). During Phase I we developed an Electrical Engineering Course on Bachelors Level for this target group. The intake of the first batch of students was in 2013. Phase I was completed in 2015 . Currently 53 students from three consecutive batches of students are enrolled. The first batch will finish their studies in summer 2017 [2].

After successful evaluation of the achievements reached in the first phase we were called to apply for funding of a second phase of our Project (Open-e-University). In Phase II our strategic target is to create a sustainable infra-structure for life-long learning at the partner Universities HS-Darmstadt and HS-Aschaffenburg. Key project goals hence are research on and development of new study programs in fields related to electrical Engineering, but with broader interdisciplinary orientation. Besides that further issues are support and assistance for non-traditional students, research on performance and study success of our students in

Manuscript received April 13, 2016; revised January 13, 2017. This work was supported in part by the German Government Ministry of Research and Education (BMBF) and is part of the Research Program "Aufstieg druch Bildung: Offene Hochschulen".

The authors are with the Faculty of Electrical Engineering, Hochschule Darmstadt, Birkenweg 8, D-64295 Darmstadt, Germany (e-mail: bernhard.hoppe@h-da.de,raphael.kurz@h-da.de). the B.Eng. program developed in phase I, as well as continuous improvement of teaching methods and e-learning material used [3].

In this paper we focus on the topic new study programs. In particular we will discuss the development of a new M.Eng-Course in "System Reliability, Quality and Security", abbreviated in the following with Q\&R, to be offered by our university HS-Darmstadt. This interdisciplinary subject requires fewer prerequisites from sciences and mathematics as e.g. an Electrical Engineering Master and is therefore better suited for students with not necessarily a Bachelors diploma but a practical qualification. The course structure as well as the main didactical strategies will be the same as in the Bachelors Program from phase I. [4].

The main project target of our partner university (HS Aschaffenburg) in phase II is the development of another Bachelors Course in Engineering and Economics, an interdisciplinary field as well.

The faculty of Electrical engineering at the University of Applied Sciences in Darmstadt offers distant learning programs since 2007. A M.Sc.-course in Electrical Engineering (M.Sc. in EE) was launched in 2007 with nearly 200 students currently enrolled. Learning organisation and teaching methods developed for this course are well investigated, thoroughly evaluated and continuously improved according to the needs of our part time distant learners and are a sound basis of generic procedures for technical further education programs. These approaches were applied and refined during Phase I in the development of the Bachelors Program in EE.

In this paper we describe motivation, content and status of development of the above mentioned Master's Course in Q\&R.

\section{LIFE-LONG EDUCATION IN Q\&R}

\section{A. Demand from Industry and Society}

Quality and reliability of technical products and systems is a key issue for mature industrial societies. Enterprises, driven by innovation, produce mainly dedicated and high-end technical goods, which however are consumed by a society which is sensitive for (unwanted) technology related consequences. Only systems with fulfilling the highest safety and reliability requirements will hence be commercially successful. Moreover the costs (in money or human lives) of lack of safety and reliability are huge; see for instance the ignition key problem of GM-cars, which was linked to over one hundred confirmed deaths. GM had to pay 900 million US\$ to end a criminal inquiry [5]. 
Impacts of new technologies and new products cannot be easily predicted until the technology is extensively developed and widely used. Therefore ongoing research in industry and academia is performed to predict, quantify and of course avoid risks inherent in technological products, as well in complex systems. Typically we encounter here mutual interference of software, hardware, mechanical subsystems as well as human factors, which create a complicated network of failure causes, which have to be eliminated. The primary objective is to prevent systems in failure conditions to be hazardous to the environment or even to injure people. Several stadards have been released by international standardization committees, like IEC 61508 and its derivatives. Also dedicated strategies for failure avoidance and safety improvements are now standard procedures in industry, e.g. FMEDA (Failure Modes Effects and Diagnostic Analysis [6]).

\section{B. Academic Programs in $Q \& R$}

Though the significance of Q\&R to society and economics is obvious, only few dedicated university programs exist in academia to train and sensitize engineers for the subject. In Germany we have only two university courses (Bachelor-with consecutive Master-Program) and a B.Eng.-Course offered by a Polytechnical University. There are no distant learning courses available for practitioners leading to an academic degree and scarce short time trainings in $\mathrm{Q} \& \mathrm{R}$ offered by private/public institutions on specific issues of the field.

Hence Q\&R is a promising subject for designing a new part time, distant learning Master of Engineering-Program, which covers the subject in a broad perspective with a life-long learning orientation. The interdisciplinary character of Q\&R may attract students with a general engineering background and/or practical experience. Moreover it will be an interesting course for graduates from our Bachelors Courses in Electrical Engineering or the future course in Engineering and Economics, which is in development at HS-Aschaffenburg.

\section{Program-DEVElopment}

Creation of a Masters-Program on Q\&R has to deal with the initial challenge that there are only very few potential lecturers in the faculties of Electrical Engineering and for Mechanical Engineering of our university with a scientific or at least a practical background in this subject. Therefore it is mandatory to find academic or industrial partners to fill this gap. During the preparation process of the funding proposal for phase II we discussed this issue with Q\&R-engineers working in safety relevant industries (Automotive OEMs, Companies for Process Control Equipment) and with scientists form Fraunhofer Research Institute for Structural Durability and System Reliability (LBF). From academia we succeeded to establish cooperation with the Distant and Independent Study Centre (DISC) at the Technical University Kaiserslautern and with HRW (Hochschule Ruhr West). Almost every second lecturer for the new Q\&R-course hence is an experienced industrial practitioner or an industrial scientist.
The standard flow for developing a new distant learning program consists of several successive phases and tasks shown in Fig. 1, [7]. The different steps will be discussed in detail in the following subchapters

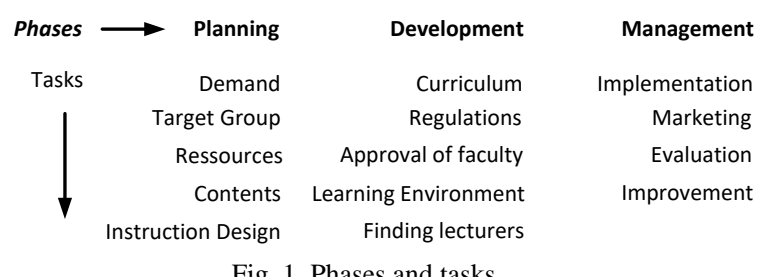

\section{A. Planning Phase}

Planning started already during the writing of the funding proposal. Analysis of the market offers in vocational training and post graduate studies in Q\&R shows strong demand for such a new academic program, as was already discussed in II.B. Hence the new program "M.Eng. in Q\&R" seems to be a promising addition to our existing distant learning courses.

The target group which was identified is engineers from industry with a Bachelor's degree and graduates from Bachelor in Electrical courses (both distant learning as well as full time traditional studies). Vocational training on a certificate basis using modules from the full Master's Program will also be offered.

Resources for the new program are limited mainly by the face to face classroom phases, which are essential for engineering subjects. Here laboratory work and direct contact with lecturers are important to deepen understanding and to construct new knowledge. Classrooms and labs are used by all of the study programs of our faculty and it is not trivial to find appropriate time slots for distant learning students. One research question hence is to virtualize laboratory phases by developing methods and tools enabling students to do experiments at home. Several so called lab@home scenarios are under investigation.

\section{1) Contents}

Content is critical for a successful program adapted to the current needs of industry and society. The German Engineering Institute (VDI, Verband Deutscher Ingenieure) has published a white paper, VDI4002, where main qualification goals for academic programs in $Q \& R$ are outlined [8]. We followed these suggestions and identified five main competence areas which have to be mastered be future Q\&R-Engineers:

1) System Engineering Methods

2) Qualitative and Quantitative Methods of Reliability Engineering

3) Functional Safety

4) Quality Management and Human Factors

5) Economic and Legal Aspects of Q\&R

Nontechnical subjects and foundations of $Q \& R$ from sciences and mathematics are to be taught during the initial phase of the studies. This will level diverse prerequisites and experiences of the applicants. Project work is mandatory for practical exposure with standards and established Q\&Rprocedures.

2) Instruction design 
The University of Applied in Darmstadt (Faculty of Electrical Engineering) offers part time distant learning courses since 2007, starting with a M.Sc. Program in Electrical Engineering. The course has 120 ECTS Credit Points (CP) and is taught over six semesters. The instruction design of this successful program is rather generic and well-adjusted to the requirements of technical academic programs [9]. It is used for the Bachelor's Course from phase I and will be transferred to both the Q\&R-Masters and the Bachelors Course in Economics and Engineering. The Design is based on a work load of $20 \mathrm{CP}$ per semester, corresponding to 500 to 600 hours of study. This is two thirds of the workload of full time students, since students in life-long learning programs normally are working also full time. Hence our new Master's Course in Q\&R with 120 Credits (corresponding to four semesters in full-time) is stretched to six semesters (Fig. 2). The allotted time for the thesis is nine month instead of six.

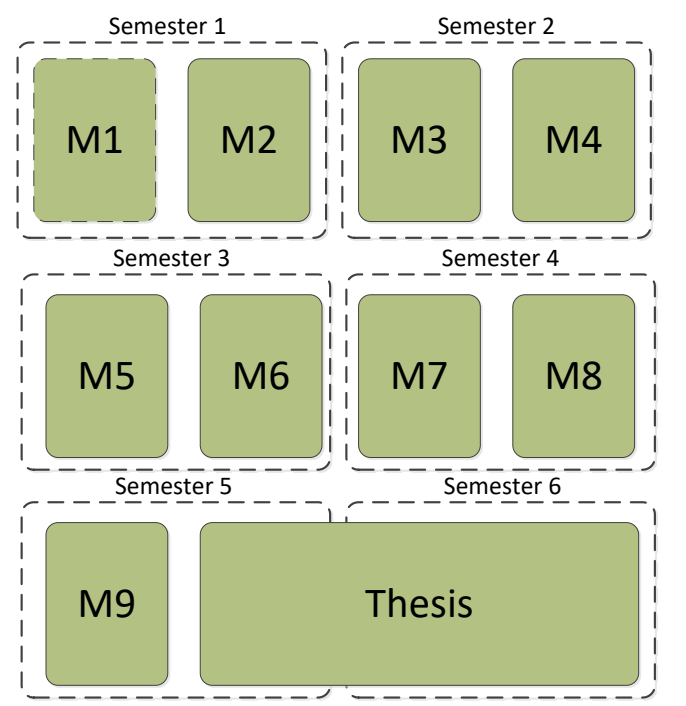

Fig. 2. M1: Communication, M2: System Design, M3: Foundations of Q\&R, M4: Reliability, M5: Functional Safety, M6: Quality Management and Human Factors, M7: Optional subjects, M8: Team Project; M9: Economics and Law; M10: Thesis (duration 9 months).

We will use the same blended learning approach as in M.Sc.EE and the Bachelors Course from phase I. Each module (except for the thesis) is divided into four submodules, which cover $25 \%$ of the module content. For teaching we use printed lecture notes with around 100 A4 pages, including exercises, quizzes, links to additional material and literature. For each submodule we will have a dedicated one day face to face training day at the university. In total there are eight days of teaching offered at the university per semester, grouped in four weekends. The printed material is closely linked to e-learning-material to be found in Moodle, our learning platform. Typically we will offer screen recordings of the face to face training, exam-papers, slides and sample solutions of the exercises from the lecture notes. Fig. 3 shows the semester time line and our learning scenario.

\section{B. Development}

If the general content of the course is fixed and the instruction design is determined, we can define the curriculum. A general overview with the headlines is shown in Fig. 2.

\section{1) Curriculum and admission procedures}

As in previous courses developed by us (B.Eng. EE and M.Sc. EE) we choose a fixed size for the modules, namely 10 $\mathrm{CP}$ each, which comes to two modules per semester, except for the final thesis $(30 \mathrm{CP})$. In distant learning courses for further education accreditation regulations in Germany require some non-technical subjects in the curriculum. For further education on Master's Level students have to have practical work experience as an engineer of one year at least (after the first academic degree) as a prerequisite to get admission.
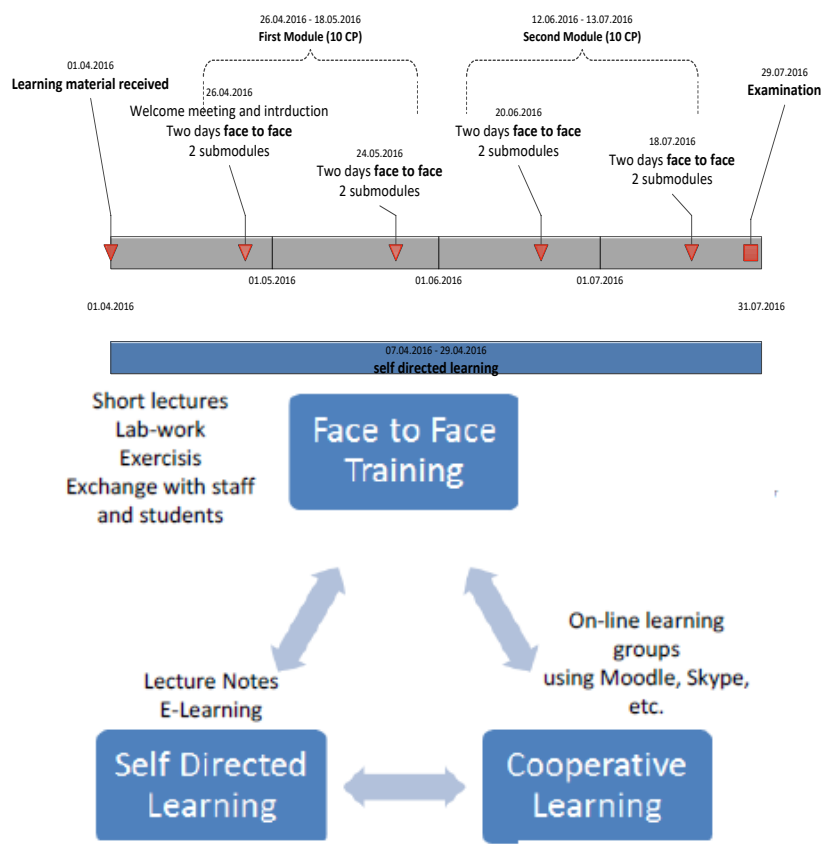

Fig. 3. Instruction design: Semester time line (top) and blended learning scenario (bottom).

\section{2) Reuse of modules for (non-)technical subjects}

Appropriate non-technical subjects may be reused from M.Sc.EE. A first candidate is the module "Communication in Industrial Teams, M1", which deals with verbal communication, technical presentation and management tasks. This module was found very useful by the students, since it offers training in a field, which is constantly underestimated. Success in teams and potential promotions depend thoroughly on communication skills. The contact weekends are filled with role plays and practical work which fosters the cohesion in the student group. Self-organized and stable student-learning teams are established during this module.

Another module with a non-technical perspective to Q\&R can also be taken from the existing M.Sc.-EE-course: Economics and Law, M9. This module consists of two introductory submodules in Economics and two submodules discussing legal aspects of an engineer's work: labour-law and liability law. The latter is of central importance in the context of Q\&R and will to be taught by a lawyer from large chemical company.

There are some other promising options for reuse of existing modules from the distant learning M.Sc. EE: One is the Module M2: System Design and the other is M8: A Team project. M2 deals with methods used for designing complex 
software based systems, which are prone to Q\&R-problems, since complexity causes inherent flaws, which may not be detected during testing and verification. The aim here is to sensitize the student for challenges resulting from complexity and to make him/her familiar with design-processes used, in particular with their weaknesses, when it comes to design safety relevant products. The other module M8 conveys in the M.Sc. EE-syllabus methods of Project Management (2.5 $\mathrm{CP})$ and a team project $(7.5 \mathrm{CP})$. For $\mathrm{Q} \& \mathrm{R}$ the use of standards like IEC 61508 or ISO26262 is of central importance. Hence a new submodule $(2.5 \mathrm{CP})$ which focusses on working with standards is included, leaving five credits for a slightly smaller team project $(5 \mathrm{CP})$.

\section{3) $Q \& R$-specific modules}

The core contents of our course are taught in modules M3 to M7. M3 is an introductory module laying the foundations in materials science, statistical and stochastic methods and basics of Q\&R-methods. Module M4 focusses on reliability of technical systems. We present quantitative and qualitative approaches to system-reliability, discuss particularities of electro-mechanical systems and investigate physical and chemical causes for system-failures.

M5 deals with functional safety, i. e. methods for handling failure conditions in active systems in such a manner to prevent unacceptable risk of injuries or damage caused by system malfunction or operator errors [10]. Use cases for functional safety are taken from electrical systems and software related safety issues of embedded systems.

In M6 human aspects are taken into account. Methods of Quality Management are presented, which improve quality of work in institutions or enterprises by laying out a framework for process design. Human factors, the second part of M6, play a prominent role in systems failures and accidents see e.g. the latest railway accident in Germany where 11 people died because an operator allowed two trains to run in different directions on a one way track.

M7 offers optional subjects. The students have to choose four submodules with technical or non-technical content related to Q\&R. Here we start with optional subjects from the M.Sc. in EE-course and we will develop additional submodules in the future.

M8 is, as mentioned above, the module where standards and project-management issues are taught and are deepened with practical work in a student team project, where a safety-relevant system has to be specified according to the relevant standards.

The last module M9 covers economic and legal aspects of Q\&R, as already described.

\section{4) Thesis}

Thesis is to our experience the most challenging part for the students in a distant learning part time program. Thesis projects have to resemble the state of the art in the field. In engineering subjects typically advanced design projects are tackled. Successful completion requires a demanding and continuous involvement, which may be difficult to maintain, if you have to work full time on other subjects at the workplace. According to our experiences in the M. Sc. EE-program, we will offer counseling and mentoring during the thesis phase to help students during this critical phase of their studies.

5) Regulations and Faculty involvement

At the moment we have completed the syllabus of the course and a module- handbook which describes competences gained by the students in each module is completed. Also we have a draft version of the specific examination regulations for the course, which are an addendum to the general examination rules of the university. Syllabus and examination rules will be presented in the next meetings of the relevant committees of faculty and university for approval. In preparation we presented the ongoing progress with this project to the different institutes of our faculty, the chair-person of the board for science and teaching of the senate and our president of the university.

\section{6) Lecturers}

In our learning and teaching scenario, lecturers have to produce the learning content, to hold the face to face training phases and to conduct the examinations. Since Q\&R is a cross-disciplinary subject, the teaching staff comes from different faculties and from industry or relevant research institutes. Up to now we have positive feedback and commitment from 19 lecturers ( 9 from industry, 5 from our faculty, two from the Mechanical engineering faculty, and 3 colleagues from our partner university in Aschaffenburg). All our submodules are covered except the submodule Software Reliabilty, for which we still have not found an appropriate person.

In order to select potential lecturers, we established a board which acts as a steering committee. Board members are two colleagues from the two universities involved, one external expert on distant learning and one representative of the scientific staff.

After approval of the study and examination regulations by the relevant committees, we will start immediately with finalizing the contracts, since the time schedule is very strict. The intake of the first student batch will be the winter term in 2017.

\section{Management}

Program-management is not an issue yet, since we are currently working on the final tasks of the development cycle. It is noteworthy that further education at public universities in Germany has to be financed completely by fees, not from taxes. So students who are willing to pay tuition fees of approximately $2000 €$ per semester have to be attracted. Marketing will hence start already this summer, by presenting the new program to industrial partners and visiting relevant fairs and other events. A web-site for creating electronic awareness has already been launched.

\section{RESUltS AND CONCLUSIONS}

The current status of the development of an M.Eng.- program in Q\&R was presented. The course is to be completed in part time and with distant learning in a blended learning approach. This project is driven by the strong demand from industry and society for well-trained Q\&R-Engineers, which are able to guide project teams in product-development, maintenance and quality control. A survey showed that there are only a few offers by other institutions, so that we expect a 
promising perspective on the further education market.

A strategic goal of Phase II of the Open-e-University project is to create a sustainable infrastructure for further education at the two contributing universities. Currently we offer two courses: the B.Eng. in EE, managed by HS-Aschaffenburg and the M.Sc. EE, for which our university (HS-Darmstadt) is responsible. Both courses address a well-established classical subject Electrical Engineering. To balance fluctuating demand for traditional subjects, we found it worthwhile to broaden the perspective by developing courses with a more interdisciplinary approach. The final target is a cross-linked, demand-driven and sustainable distant learning environment (Fig. 4) for further education of electrical engineers and practitioners from related fields.

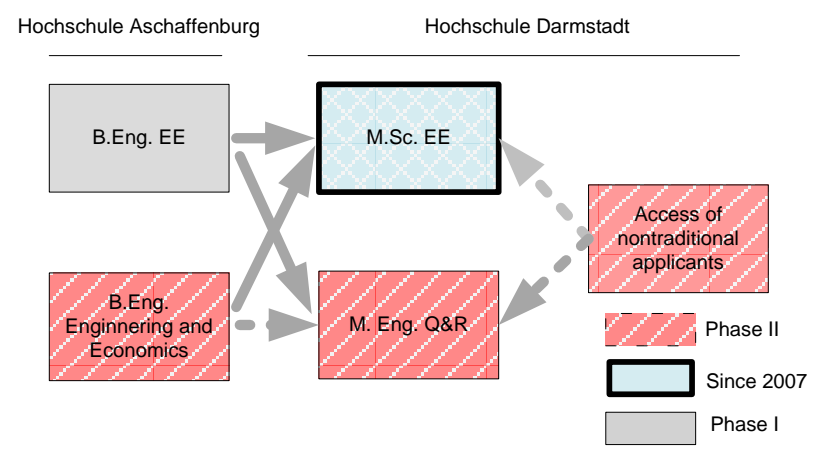

Fig. 4. Future cross linked further education environment.

The research project allows the HS-Darmstadt to develop a M.Eng.-program, that expands the training market with significant future issue. It opens the University for new target groups and fosters the establishment of more flexible learning pathways - including better transitions between the vocational education and higher education, opening universities to non-traditional students.

In this paper, the systematic approach to the development of a distance learning M.Eng.-program in Q\&R was shown. This includes the phases of the study program planning, development and management.

The new M.Eng. Course was developed under a very tough time schedule. Funding lasts only 30 months. Then the new program has to be on the market and attracting students. These challenges are met solely because we rely on a generic course structure, an established instruction design and synergistic use of modules. The new masters course has academic content on its own but is embedded in the distant learning network at the two partner universities. This facilitates resource sharing, best practice mixing and effective management structures.
[1] Hochschulen.

[Online]. www.wettbewerb-offene-hochschulen-bmbf.de

Available:

2] C. Böhmer et al., "Designing a blended-learning Bachelor's degree in electrical engineering for non-traditional students," IEEE Educon 2013, Conference Proceedings, pp. 924-927, 2013.

[3] N. Roznawski and R. Kurz, "Target-group oriented e-learning concept for a blended-learning program in electrical engineering," presented at 7th International Technology, Education and Development Conference, Valencia, Spain, pp. 147-152, 2013.

[4] B. Petendra, N. Kälberer, R. Kurz, and B. Hoppe, "E-learning concepts in distance learning for non-traditional engineering students," in Proc. 7th International Conference of Education, Research and Innovation Seville, pp. 818-826, 2014.

[5] D. Ivory and B. Vlasic. (2015). $\$ 900$ million penalty for G.M.’s deadly defect leaves many cold. The New York Times. [Online]. Available: http://www.nytimes.com/2015/09/18/business/gm-to-pay-us-900-milli on-over-ignition-switch-flaw.html?_r=0

[6] W. M. Goble, Control Systems Safety Evaluation and Reliability, Durham, North Carolina: ISA, 2010.

[7] A. Hanft, Management von Studium, Lehre und Weiterbildung an Hochschulen, Münster, New York: Waxmann, 2014, ch. 2, p. 56.

[8] Verein Deutscher Ingenieure e.V., Zuverlässigkeitsingenieur/ Zuverlässigkeitsingenieurin Berufsbild, Berlin: Beuth Verlag, 2011.

[9] A. Müller, R. Kurz, and B. Hoppe, "Development of a distance learning concept for a bachelor of scienes in electrical engineering," in Proc. 3rd World Conference on Learning, Teaching and Educational Leadership, vol. 93, pp. 1484-1488, Oct. 2013.

[10] J. Börcsök, Funktionale Sicherheit-Grundzüge sicherheitstechnischer Systeme, Berlin: VDE Verlag, 2015.

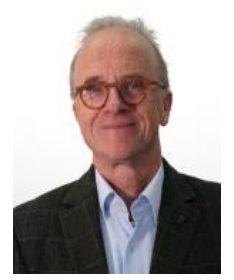

Bernhard Hoppe was born in Gelnhausen, Germany in 1955. He holds a diploma and a Ph.D. in theoretical solid state physics from Johann Wolfgang Goethe Universtät in Frankfurt/M. Germany.

After his studies he was with the central Laboratories for electronics and material sciences of Siemens AG, Munich, Germany and later with VDO Adolf Schindling AG in Schwalbach/Ts. Germany, leading the department for microelectronic circuit design. In 1993 he was appointed as a Professor for Material Science and Microelectronics at the University of Applied Sciences in Darmstadt, Germany.

He authored and coauthored more than 60 journal papers and published four books on integrated circuit design. He is a board member of the Central Committee of the ZFH (Central Institution for Distant Learning at Universities of Applied Sciences in the states Hesse, Rhineland-Palatina and Saar). He is currently course director of the M.Sc. EE and project leader of Phase II, Open-e-University. His research interests are course design of distant learning programs as well technical aspects of distant learning methodology.

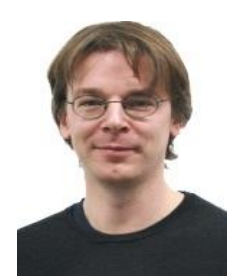

Raphael Kurz was born in Darmstadt, Germany in 1978. He holds a diploma in social pedagogy $(\mathrm{FH})$ and a master of arts in interdisciplinary media science from the University in Bielefeld/Germany.

After his diploma he worked as media educator in a youth center with disadvantaged young people and later as a freelancer in the field of e-learning.

Since 2012 he is research assistant for the BMBF-Project "Open e-University" at the University of Applied Sciences in Darmstadt, Germany. His main interests are the development of distance learning study programs for non-traditional students and the implementation of blended learning methods. He authored and coauthored more than 10 national and international journal papers.

\section{REFERENCES}

